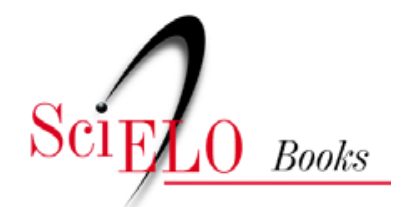

\title{
Capítulo 15 - Linguagem, interação e comunicação competências para o desenvolvimento da criança com deficiência não oralizada
}

\author{
Debora Deliberato
}

\section{SciELO Books / SciELO Livros / SciELO Libros}

DELIBERATO, D. Linguagem, interação e comunicação: competências para o desenvolvimento da criança com deficiência não oralizada. In: NUNES, L. R. O. P., and SCHIRMER, C. R., orgs. Salas abertas: formação de professores e práticas pedagógicas em comunicação alternativa e ampliada nas salas de recurso multifuncionais [online]. Rio de Janeiro: EDUERJ, 2017, pp. 299-310. ISBN: 97885-7511-452-0. Available from: doi: 10.7476/9788575114520.017. Also available in ePUB from: http://books.scielo.org/id/xns62/epub/nunes-9788575114520.epub.

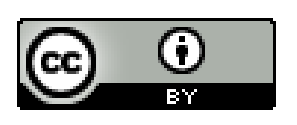

All the contents of this work, except where otherwise noted, is licensed under a Creative Commons Attribution 4.0 International license.

Todo o conteúdo deste trabalho, exceto quando houver ressalva, é publicado sob a licença Creative Commons Atribição 4.0.

Todo el contenido de esta obra, excepto donde se indique lo contrario, está bajo licencia de la licencia Creative Commons Reconocimento 4.0. 


\section{Capítulo 15 - Linguagem, interação e comunicação: competências para o desenvolvimento da criança com deficiência não oralizada}

Debora Deliberato ${ }^{1}$

\section{Introdução}

Nos últimos anos, há uma crescente preocupação por parte dos profissionais e dos pesquisadores em entender a diversidade humana. A literatura tem discutido as diferentes possibilidades em relação às habilidades de comunicação entre as pessoas, principalmente quando: a) a fala não é adquirida na sua totalidade, b) a fala não é adquirida durante o desenvolvimento infantil, e c) a fala foi adquirida e desenvolvida para representar ideias, desejos, intençôes nas diferentes complexidades, mas, por alguma interferência, a pessoa pode perdê-la ou tornar-se impossibilitada de utilizá-la com diferentes pessoas.

Quando as pessoas se deparam com crianças, jovens e adultos que não falam, a interação pode não ocorrer e, com isso, a comunicação não se efetiva. É uma situação que pode surgir no dia a dia das pessoas, como, por exemplo,

1 Docente do Departamento de Educação Especial e do Programa de Pós-Graduação em Educação da Unesp de Marília. Pesquisadora do CNPq. Livre-Docente em Comunicação Alternativa. E-mail: delibera@marilia.unesp.br. 
no ambiente escolar, quando na sala de aula há um aluno com deficiência sem oralidade (ausência da fala).

Interação e comunicação fazem parte da rotina escolar. O professor deve estar atento à rotina de seus alunos para promover situações e atividades nas quais todos possam participar. Além da importância da interação e comunicação na rotina de sala de aula, o docente deve estar atento para a função da fala no processo da aprendizagem da leitura e da escrita, principalmente quando se trabalha com uma língua de natureza alfabética, como no caso da língua portuguesa. Entender o processo de aquisição de um idioma e da função da fala faz parte de uma função de complexidade maior, que é a linguagem.

Pesquisadores discutiram a necessidade de o professor entender a aquisição da linguagem e sua importância para as habilidades de comunicação, interação e aprendizagem da leitura e da escrita. Deliberato et al., (2014) alertaram que, quando o professor entende a função da linguagem para o desenvolvimento da comunicação e interação, a sua mediação poderá ser adequada para as diferentes especificidades dos alunos da sala de aula.

A linguagem é uma função mental superior que nos possibilita captar informações do meio ambiente por meio dos canais sensoriais e, em seguida, a pessoa pode processar esses estímulos recebidos nas diferentes regiōes cerebrais. Após todo processo de entrada de informações, há um complexo intercâmbio com outras funções mentais, tais como atenção, percepção, memória e cognição, que permitem ampliar todo o conteúdo da linguagem de forma dinâmica (Luria, 1981).

Assim, é por meio da percepção, integração e organização da informação recebida do meio ambiente que o indivíduo vai organizar seu pensamento mediante um sistema simbólico, linguístico, de alta complexidade. Esse sistema linguístico tem dependência com a língua, o idioma, da comunidade à qual pertence o indivíduo. Cada língua tem suas características: semântica, lexical, sintática, morfológica, fonológica e pragmática. Sendo assim, a linguagem comporta duas faces: organização de um idioma (língua: processo mental) e as habilidades de externalizar todo o conteúdo pensado e organizado mentalmente, por meio da linguagem externa, que pode ser a fala e $a$ escrita (Saussure, 1991). 
A fala ou linguagem oral é a habilidade mais utilizada e esperada no desenvolvimento da criança, quando se pensa nas habilidades de comunicação no contexto da modalidade oral. A fala é uma habilidade complexa que necessita de várias outras funçôes para que a criança possa se apropriar e transmitir seu pensamento e ideia com intencionalidade. A fala é a expressão do conteúdo organizado por meio do idioma aprendido. A criança precisa compartilhar, vivenciar as normas da língua/idioma durante as situações dialógicas, ou seja, nas diferentes interações, a criança pode e deve compartilhar com os interlocutores competentes o uso do idioma aprendido.

Comunicação é a capacidade que o ser humano tem de trocar informações aprendidas e pretendidas com diferentes pessoas. É um processo que envolve um receptor e um emissor, ou seja, uma pessoa emite uma mensagem, e a outra recebe a mensagem e a interpreta para responder com coesão e coerência. Durante o processo de comunicação, é importante o uso de um sistema linguístico compartilhado, ou seja, ambos os parceiros de comunicação devem utilizar o mesmo idioma para que possam transmitir e compartilhar uma mensagem. A comunicação humana torna-se possível por meio da compreensão dos diferentes signos compartilhados pela comunidade, ou seja, a comunicação será efetivada por meio do uso de um sistema de representação compartilhado no grupo.

A comunicação é mais efetiva quanto maior e melhor o sistema compartilhado entre os interlocutores: parceiros de comunicação.

\section{Aspectos gerais a respeito da competência comunicativa}

As experiências que as crianças e jovens têm durante seu desenvolvimento são dependentes da mediação e do suporte oferecido pelo meio de que participam. A família e a escola fazem parte desse cenário, facilitando e proporcionando acesso ao conhecimento. A participação das crianças em diferentes situações pode favorecer a ampliação do vocabulário, assim como propiciar a vivência no contexto cultural com a língua, o idioma da sua comunidade, como no caso da língua portuguesa.

Argyle (1976), em seus estudos, argumentou que a linguagem emerge na interação social, e os "componentes linguísticos" tornam-se importantes 
para a transmissão e a coordenação do pensamento individual e para o desenvolvimento e a transmissão de cultura. Segundo o autor, para duas pessoas se comunicarem por meio da linguagem, é necessário que elas usem as palavras da mesma forma, convencionadas pela língua vinculada à sua cultura: "A língua real aprendida é aquela que se desenvolveu, durante um longo período de desenvolvimento cultural, na cultura da criança" (Argyle, 1976, p. 77).

A aquisição e o domínio da língua portuguesa fazem parte de um processo de experiências vividas no meio cultural, no qual a criança passa, de agente passivo, à medida que absorve o que escuta, a agente ativo, construindo suas ideias, intenções e desejos. A partir dessa construção e elaboração interna, organizada por meio das regras do idioma, a criança expressa uma ideia com conteúdo e estrutura que pode ser compreendida por um adulto ou por uma outra criança em pleno desenvolvimento.

A troca de experiências entre as crianças com os diferentes interlocutores, mediada e assistida nas situações dialógicas, propicia o acesso destes ao conhecimento e permite às crianças e aos jovens o constante uso do idioma da comunidade em que vive. Quanto mais a criança participa das situaçôes dialógicas, mais ela compartilha experiências em relação ao seu idioma e suas regras: semântica, fonológica, sintática, morfológica e pragmática.

À medida que o desenvolvimento da criança acontece, diferentes habilidades são conquistadas e novas competências são adquiridas. Toda criança tem capacidade de aprender novas habilidades, mas elas dependem da mediação oferecida no meio ambiente que participam. $\mathrm{O}$ incentivo e o reforço oferecidos por diferentes pessoas podem proporcionar às crianças avanços nas aquisições das diferentes competências para o desenvolvimento global e da linguagem.

A ampliação do vocabulário e o entendimento em relação ao uso da língua portuguesa acontece na relação com o outro, ou seja, durante as situações dialógicas: é no momento em que a criança recebe a informação do outro (receptor) que ela pode elaborar e expressar uma resposta com intenção (emissor). Nesse movimento que ocorre durante a interação com o outro, há troca de informações, ou seja, existe a comunicação e a criança aprende a usar um sistema linguístico que representa seus sentidos, suas intenções. Quanto mais experiências e oportunidades a criança vivenciar durante os primeiros anos de vida com diferentes interlocutores, mais competências serão adquiridas em relação às habilidades de comunicação e expressão. 
Toda criança deve receber o suporte do meio ambiente para que possa adquirir e desenvolver as diferentes competências. A capacidade que cada criança apresenta pode ser explorada e ampliada para ter sua função nas diferentes atividades vivenciadas.

A família, sem dúvida, é a base para o início, o acompanhamento e os avanços no desenvolvimento de seus filhos e deve ser o parceiro fundamental no momento da entrada da criança na escola. É no meio familiar que os primeiros modelos e suportes são oferecidos às crianças, nos diferentes aspectos, em relação aos desenvolvimentos motor, cognitivo, linguístico, afetivo e social. A entrada da criança na escola amplia as possibilidades do desenvolvimento, e cabe a esse estabelecimento de ensino oferecer recursos e procedimentos para o aprendizado da leitura e da escrita.

A criança que inicia o processo escolar com competências já adquiridas anteriormente pode ter mais habilidades no entendimento em relação às estratégias utilizadas na medição do professor no processo de ensino dos diferentes conteúdos e em relação ao entendimento da palavra impressa (Deliberato e Nunes, 2015).

\section{Competência comunicativa em relação à criança com deficiência não oralizada}

Quando se discute a mediação em relação à criança com deficiência, os pais devem estar atentos às especificidades do seu filho para que o modelo a ser oferecido no momento das situaçóes dialógicas possa de fato proporcionar a aquisição de competências. A criança com deficiência pode ter habilidades diferentes em relação ao esperado e, dessa forma, as pessoas podem não perceber as diferentes capacidades de cada uma delas.

As crianças com deficiência podem ter capacidades para desenvolver habilidades diferentes das esperadas no desenvolvimento infantil em razão das suas especificidades sensoriais, perceptivas, motoras, cognitivas e linguísticas. Seria possível observar crianças com deficiência desenvolvendo outras habilidades de comunicação no momento das situações dialógicas, como, por exemplo, olhar, gestos, expressóes corporais, vocalizaçóes, uso de objetos, imagens pictográficas e até o uso da escrita como forma de expressar suas 
intenções, quando não conseguem utilizar a fala (Deliberato, 2015; Nunes, 2003; Limongi, 2002).

Entender e participar da diversidade de habilidades comunicativas compartilhadas entre as pessoas pode ampliar a construção de um sistema linguístico mais estruturado e favorecer o desenvolvimento das competências das crianças com deficiência. Nesse contexto, a família e a escola exercem papéis fundamentais.

Von Tetzchner et al. (2005) discutiram que a escola, principalmente a educação infantil, pode ser o ambiente favorecedor para dar suporte às linguagens alternativas. Na escola, a criança com deficiência pode ter a oportunidade de vivenciar com diferentes interlocutores o uso de sistemas que representam sentidos nas situações dialógicas, nas diferentes tarefas previstas na rotina de sala de aula.

A literatura discutiu que, quanto mais diversificado o vocabulário da criança com deficiência, mais possibilidades e oportunidades de ela entender a rotina de atividades da sua sala de aula e o conteúdo previsto no planejamento diário. $\mathrm{O}$ professor deve estar atento em relação às etapas do desenvolvimento de seu aluno para poder planejar e adequar o conteúdo do seu programa de ensino (Schirmer e Nunes, 2011).

Quando a criança com deficiência não conquista a fala como habilidade de expressar suas intenções, desejos e ideias, a ampliação do vocabulário e a organização desses elementos em estruturas mais organizadas, como frases, orações e textos, podem estar prejudicados.

Grande parte das crianças e jovens com deficiência e sem a oralidade acaba desenvolvendo, no seu meio social, outras habilidades de expressar suas ideias. Isso pode acontecer com diferentes crianças com deficiência que utilizam o olhar, expressão facial, sons vocais (vocalização) e gestos não padronizados, que normalmente são compreendidos por interlocutores familiarizados com as habilidades e com o contexto de uso. Essas habilidades são importantes para o desenvolvimento da linguagem, da comunicação e da interação, mas não são suficientes para a complexidade da função da linguagem (Romski e Sevcik, 2005).

A literatura argumentou o quanto é importante a família incentivar diferentes habilidades de comunicação para que as crianças com deficiência, não oralizadas, possam participar das situaçôes de interação com diferentes interlocutores; entretanto, Harwood et al., (2002) também argumentaram a 
necessidade da aquisição de estruturas mais complexas para a criança e para o jovem com deficiência conquistar as diferentes funçôes da linguagem.

Deliberato (2009, 2015) e Sameshima e Deliberato (2007) evidenciaram que crianças e jovens com deficiência, principalmente aqueles com deficiência neuromotora, mais especificamente com a paralisia cerebral, utilizam gestos, expressões faciais e vocalizaçôes como sendo as únicas possibilidades reais de comunicação, mesmo que em ambientes preestabelecidos, como no caso da rotina. Nesse contexto, eles acabam não participando das situações dialógicas de forma mais efetiva com diferentes interlocutores, ou seja, são passivos nas situações de interação e dependem de outro interlocutor competente no entendimento de suas habilidades para fazer a mediação.

A área da Comunicação Suplementar (Ampliada) e Alternativa instrumentaliza a pessoa com deficiência não oralizada nas situações de interação e comunicação. Perante o uso dos sistemas suplementares e alternativos de comunicação, a pessoa com deficiência pode compreender diferentes conteúdos e organizá-los para expressá-los de forma mais estruturada e, assim, pode interagir e ampliar a comunicação com diferentes interlocutores. Sendo assim, o uso dos sistemas suplementares e alternativos de comunicação são utilizados para diferentes pessoas com deficiência a fim de ampliar as questões de compreensão, elaboração e produção de novas ideias (Von Teztchner, 2009; Rothschild e Norris, 2001).

Light e McNaughton (2013) destacaram a relevância dos sistemas de comunicação suplementar e alternativo não só ao propiciarem uma variedade de funçôes pragmáticas, mas também ao desenvolverem um potencial para a aquisição e aprimoramento da linguagem e facilitarem as competências subjacentes à compreensão e à produção da linguagem gerada.

Sevcik, Romski e Wilkinson (1991) discutiram que a aquisição de símbolos faculta à criança o acesso para representar o meio externo internamente, além de proporcionar significados para compartilhar percepções internas e sentimentos com os outros. Ainda nessa direção, pesquisadores como Iacono et al. (1993) discutiram que a comunicação pode ocorrer por meio de múltiplas modalidades e, embora seja importante esse fato para se destacar, a interação humana é caracterizada pela comunicação simbólica, isto é, envolve o uso de símbolos arbitrários que representam ideias, estados afetivos, objetos, ações, relações e eventos. A capacidade de utilizar símbolos permite 
ao indivíduo tanto a comunicação a respeito de ideias e sentimentos quanto sobre temas que estão temporal e espacialmente distantes.

Para Millikin (1997), as pessoas combinam estratégias verbais e não verbais no momento da comunicação, favorecendo, dessa maneira, mensagens comunicativas que tenham sentido para o ouvinte. Segundo a autora, a pessoa com deficiência que usa sistemas suplementares e alternativos de comunicação pode transmitir mensagens por intermédio de sistemas de representação e elementos não verbais.

Em relação aos sistemas suplementares e alternativos de comunicação, Millikin (1997) padronizou uma estrutura de modelo no contexto das categorias dos métodos para a linguagem verbal: com auxílio (auxiliada) e sem auxílio (não auxiliada). Uma técnica de comunicação verbal auxiliada envolve a presença de um objeto físico externo, como papel, lápis, computador, pranchas com figuras ou ainda um dispositivo eletrônico para comunicação suplementar e alternativa (vocalizador ou comunicador). A comunicação verbal não auxiliada está associada à técnica que não precisa de objetos externos, como no caso da fala e da linguagem de sinais.

A autora ainda estabeleceu duas subcategorias para a comunicação verbal com auxílio e comunicação verbal sem auxílio: vocal e não vocal. Considerou a comunicação verbal, sem auxílio e vocal, a fala, enquanto a língua de sinais seria a comunicação verbal sem auxílio e não vocal. A comunicação verbal com auxílio e vocal trata-se do uso de sistemas de comunicação com voz digitalizada ou sintetizada, vocalizadores com voz digitalizada e sintetizada. Já a comunicação verbal com auxílio e não vocal engloba a linguagem escrita, as pranchas com alfabeto e as pranchas com figuras.

Ambas as modalidades de comunicação verbal, auxiliada e não auxiliada, apresentam um grupo ou um sistema de símbolos para a elaboração e transmissão das mensagens, ou seja, o termo verbal está relacionado com um referente simbólico específico. No caso de indivíduos para quem os referentes são ações e comportamentos que comunicam mensagens específicas, mas não representam referentes específicos, Millikin (1997) designou como comunicação não verbal. Para essa categoria, a autora elegeu duas subcategorias: vocal (choro, vocalização, variação de entonações, risada) e não vocal (apontar, gestos, expressões faciais e linguagem corporal).

Lloyd e Karlan (1984) salientaram que gestos, linguagem corporal e vocalizações, designados como comunicação não verbal por Millikin (1997), 
estão ligados a um grupo de símbolos, e não a um sistema de símbolos, isto é, tais grupos de símbolos são relativamente finitos e determinados, e faltam regras específicas ligadas à possibilidade de combinação, restringindo as mensagens que um indivíduo poderia ser capaz de transmitir.

\section{Ler e escrever: questões em relação à criança com deficiência que usa a Comunicação Alternativa}

Sandberg (2016) argumentou que ler e escrever estão entre as habilidades adquiridas mais importantes na nossa sociedade, permitindo-nos o acesso à informação independentemente da distância e do tempo. A autora ainda reforçou que a aquisição das habilidades da leitura e da escrita permitem às pessoas: a) participar de forma mais ativa na sociedade; b) obter mais informações; c) conquistar e ampliar a comunicação; d) ser educada; e) desenvolver atividades vocacionais; e f) desenvolver atividades de lazer. Sendo assim, a aprendizagem da leitura e da escrita é uma das principais conquistas do desenvolvimento da criança.

A literatura tem discutido que o uso da escrita pode ser um caminho para que as pessoas com deficiência, usuárias da Comunicação Alternativa, acessem o vocabulário ilimitado da sua comunidade e, assim, tenham a possibilidade de participar das diferentes situações dialógicas e do processo escolar (Nunes et al., 2011; Schirmer e Nunes, 2011; Smith, 2003). A mesma literatura e a experiência prática com professores e familiares de crianças e jovens que usam os sistemas suplementares e alternativos de comunicação indicaram dificuldades no caminho para a aquisição e para o desenvolvimento da leitura e da escrita dessas crianças e jovens (Deliberato, 2009; Lund e Light, 2006; Smith, 2003).

A literatura destacou que o professor deve ter o conhecimento a respeito da complexidade da relação entre a linguagem escrita e a linguagem oral: a primeira trata-se de sistemas de signos que representam a linguagem oral de forma gráfica e permanente, como, por exemplo, a escrita logográfica, quando o signo gráfico representa uma palavra; a escrita de sílaba, quando o signo escrito representa uma sílaba falada, e a alfabética, quando a combinação de signos corresponde aos sons da linguagem falada (Sandberg, 2016). 
Sendo assim, a linguagem escrita tem um vínculo fundamental com a linguagem oral e requer da criança um alto grau de abstração e poder de análise para converter os sons, fonemas e, nas representações gráficas, os grafemas. Além da tarefa de codificar e decodificar os fonemas e grafemas, a criança precisa compreender o sentido da "palavra" falada ou escrita. No processo de aquisição da leitura e da escrita, as pessoas podem utilizar duas estratégias para decodificar as palavras: ortográfica e fonológica. Na estratégia ortográfica, a pessoa pode visualizar a palavra impressa e entender seu significado, principalmente porque já tem o conhecimento do vocabulário e da representação entre os fonemas e grafemas. Mas, quando as palavras não são familiares, há necessidade da estratégia fonológica.

$\mathrm{Na}$ rota fonológica, as letras precisam ser reconhecidas na sua forma fonológica, ou seja, como fonemas: cada letra tem a correspondência do som (relação fonema/grafema). As experiências fonológicas são armazenadas na memória de curto prazo, e são as diferentes experiências entre a constituição da produção dos fonemas durante o uso na fala que vão constituindo a memória fonológica. É a relação entre a produção oral e a experiência com os sons da língua, ou seja, a criança vai aprendendo a emitir e a ouvir, a discriminar e a ter a consciência de cada som - consciência dos fonemas da sua língua.

No momento da aprendizagem da leitura e escrita, devem ser considerados vários fatores: a) experiência e uso do idioma da comunidade a que pertence a criança; b) cognição; c) memória visual e auditiva; e d) diferentes aspectos da linguagem, como: vocabulário, conhecimento da organização sintática e aspectos fonológicos e pragmáticos.

Pesquisadores advertem que a criança e o jovem que usam a Comunicação Alternativa acabam apresentando dificuldades no processo de aprender a ler e a escrever em decorrência de: a) vocabulário limitado; b) falta de vivência com as estruturas do idioma da comunidade das quais participam; c) falta de vivência da produção e da articulação dos fonemas do idioma; d) falta de retroalimentação entre sua produção e monitoramento auditivo do fonema; e) ausência de correspondência entre o input do idioma vivenciado e o uso dos sistemas gráficos utilizados por eles; e f) ausência de parceiros de comunicação competentes para usarem os sistemas gráficos a partir da estrutura do idioma compartilhado. A falta de suporte constante nas situações dialógicas pode interferir nas experiências das crianças e dos jovens que usam 
a Comunicação Alternativa com os elementos linguísticos necessários para a constituição da linguagem.

Os estudos a respeito da aprendizagem da leitura e da escrita em crianças e jovens que usam a Comunicação Alternativa ainda possuem número restrito de participantes e são resultados baseados em estudo de casos (Light e MacNaughton, 2013). Esses estudos tratam a respeito das dificuldades em relação à decodificação e à compreensão da palavra impressa e discutem a interferência ou não da habilidade da consciência fonológica (Sandberg, 2016; Van Balkom e Verhoeven, 2010).

Embora a literatura tenha discutido fatores individuais que possam interferir no processo de aquisição e desenvolvimento da leitura e da escrita, autores advertem que a escrita é uma invenção cultural e, como tal, é transmitida no contexto cultural e social. Nesse sentido, as pesquisas discutiram que crianças que exploram a escrita desde muito cedo, que participam de leituras de livros e crianças cujas famílias proporcionam experiências com a leitura podem apresentar expectativas diferenciadas em relação à aquisição e ao desenvolvimento da leitura e da escrita (Soto et al., 2008; Guarda e Deliberato, 2006).

Sendo assim, cabe aos profissionais da educação e da saúde terem o cuidado de avaliar e acompanhar as habilidades de seus alunos, bem como entender a história de vida construída durante as diferentes etapas do desenvolvimento. Os estudos demonstraram a necessidade de programas individualizados em razão da diversidade de habilidades e características identificadas em crianças e jovens que usam a Comunicação Alternativa. Além das questôes de recursos e procedimentos direcionados à consciência fonológica, decodificação e compreensão da palavra impressa, o uso da tecnologia também tem sido apontado como um instrumento favorecedor no processo de aprendizagem, como, por exemplo, nos recursos com saída de voz sintetizada ou digitalizada. Mas a literatura também tem alertado para a necessidade de intervenção para cuidar dos aspectos socioculturais, de motivação e de atenção das crianças e jovens que usam a Comunicação Alternativa (Light e McNaughton, 2014, 2015; Rocha et al. 2015). 


\section{Considerações finais}

A linguagem é uma função mental de alta complexidade, pois interage com outras funções mentais, como a memória e a cognição, e está intimamente relacionada com as ações do meio ambiente - suporte do interlocutor. Os profissionais que atuam com crianças e jovens com deficiência necessitam entender a respeito da aquisição e do desenvolvimento da linguagem e das diferentes possibilidades de a pessoa com deficiência expressar seus desejos, suas intenções e ideias. A construção da linguagem e a vivência com o idioma são compartilhados nas situaçôes dialógicas. Cabe ao interlocutor competente no idioma da comunidade oferecer o suporte em relação às linguagens alternativas. Nesse contexto, a escola é um ambiente favorável para inserir as linguagens alternativas e, com isso, as pessoas com deficiência podem ter acesso às situaçôes dialógicas e ter voz nas trocas comunicativas.

Vivenciar os elementos linguísticos da linguagem, por meio do suporte das açōes dos interlocutores competentes nas linguagens alternativas, motiva as pessoas com deficiência que usam a Comunicação Alternativa a emergir na aprendizagem da leitura e da escrita. $\mathrm{O}$ professor, compreendendo a função da linguagem, pode elaborar e adaptar seu currículo para a diversidade de alunos com deficiência sem oralidade e favorecer a aquisição da leitura e da escrita. 